\section{Stony Meteorite of LavRentievka}

On January 11, 1938, at about 10.30 U.T., a meteorite of a lens-like shape, weighing about $1 \frac{1}{4} \mathrm{kgm}$., was seen to fall near the village of Lavrentievka, Orenburg region $\left(52^{\circ} 27^{\prime}\right.$ N.; $51^{\circ} 34^{\prime}$ E. $)$.

The meteorite fell within a distance of 18-20 metres from T. A. Zhigunov, a hunter, who picked it up immediately. Previous to the fall this witness heard in a northerly direction a din with three detonations following each other at equal intervals, each subsequent stroke being stronger than the one preceding it.

The detonations preceding the fall of the stone were heard by many of the inhabitants of the village of Lavrentievka and other neighbouring villages. However, neither T. A. Zhigunov nor anyone else observed any light phenomena, although the sky was perfectly cloudless.

The stone fell on a frozen ploughed soil not covered with snow; it penetrated only $5 \mathrm{~cm}$. into the soil. During the fall the stone scattered on different sides clods of frozen earth over an area up to two metres in radius ; in addition, as observed by T. A. Zhigunov, the stone itself was for some time revolving about its axis.
Two minutes after the fall, T. A. Zhigunov picked up the stone and felt it to be too hot to be held in a clenched hand; therefore he placed it on the ground; in about ten minutes the stone had cooled to such an extent that it could be readily taken in the hand.

During the fall, a small chip was split off from the stone. Later on, three more small pieces were broken from it. All these pieces, placed together with the bulk of the stone, reproduce the origina] lens-like shape of the stone.

The weight of the four fragments of the stone thus assembled is $793.60 \mathrm{gm}$. Moreover, probably $200 \mathrm{gm}$. were lost in the crushing of the stone.

The meteorite may be referred to white chondrites and contains a rather large number of chondrules and metallic grains. The mat smooth crust of the meteorite is of a black-brown colour and has no piezoglypts.

The study of this fall was made by the present writer. The five fragments of the meteorite mentioned above have been placed in the meteorite collection of the Academy of Sciences of the U.S.S.R.

E. L. Krinov.

\title{
Greek Earthquake of July 20, I938
}

GUDDENLY, and without any premonitory $S$ tremors, in the early morning of Wednesday, July 20, a very large area centred in northern Attica, Greece, was disturbed by a violent earthquake (see Nature, July 30 , p. 202), which did much damage to property and caused the deaths of twenty people and injuries to a hundred others. It is now possible to add some further details of this shock from a preliminary report prepared by Prof. N. Critikos, of the University of Athens, though the final conclusions will not be available for some time.

The first pulses to reach the seismological observatory at Athens did so at 2h. 24m. 19s. (T.m.E.O.), and thus the initial time of the shock must have been $24 \mathrm{~m}$. 13s. $\pm 2 \mathrm{~s}$. The pulses immediately succeeding these were of such violence that both seismographs at the observatory were forced from their bearings and damaged. The 1,000-kgm. Wiechert horizontal pendulum was so seriously damaged that it took several days to repair, but the $1,200 \cdot \mathrm{kgm}$. Wiechert vertical instrument was put right almost immediately, and was registering again about one and a half hours after the initial shock. This latter instrument registered small aftershocks at intervals of five or ten minutes for several hours.

The very strong tremors were felt by people in Athens to last 8-10 seconds, being preceded and accompanied by quite loud deep-toned underground rumblings. The preliminary movement appeared to be horizontal and then undulatory with a slight diminution of intensity towards the middle of the duration. It appeared to come from the northnorth-east and to be travelling to the south-southwest. On the coast at Scala Oropos, in the epicentral region, the intensity of the shock was much stronger and it also appeared to last longer. The region over which the shock was felt macroseismically extended as far as the island of Lemnos (Castro), that is, more than $250 \mathrm{~km}$. in this direction, but in the perpendicular direction scarcely $140 \mathrm{~km}$. to Lamia-Syra. Thus the epicentral region was elongated in a north-east-southwest direction. The villages affected slightly in Attica were Kakossalesi, Malakasa, Kapandriti, Kiourka and Kalamos, whilst the villages in which most damage was done include Scala Oropos (with Nea Palatia and Pontion), Chalcoutsi, Oropos and Sycaminon.

From the above evidence it appears that the epicentre was near the north coast of Attica at a distance of $42.5 \mathrm{~km}$. from Athens, and near a point having geographic co-ordinates lat. $38 \cdot 35^{\circ} \mathrm{N}$., long. $23 \cdot 8^{\circ} \mathrm{E}$. The fact that the seismic energy was propagated to a greater distance in a north-east-south-west direction, that is, in the direction of the great tectonic fault which passes between Mt. Pentelica and Mt. Parnes, suggests that there was a sudden vertical movement of this fault resulting from a positive orogenic movement.

The earthquake has been followed by numerous feeble aftershocks only one or two of which have been felt as far as Kapandriti Tatoi, Eretrie and Chalcis. Another shock, of moderate intensity, and having the same epicentre, took place on July 27d. 3h. 29m. 19s. (T.m.E.O.) and was just sensible in Athens. Slight aftershocks were continuing infrequently even on August 12.

Although Greece as a whole is liable to earthquakes, the region near and to the north of Athens has not been considered as being active seismically on a destructive scale in recent times. Modern research, however, indicates that it was probably a seismically active region during the seventh and eighth centuries A.D., and this activity appears to have been renewed in the present instance.

The damage done during the earthquake of July 20 was serious chiefly to old and/or badly constructed buildings. An interesting case concerns the primary school at Kalosalesi, the walls and roof of which appear to have moved independently, causing great damage at junctions. 